\title{
Microglia Function in Central Nervous System Development and Plasticity
}

\author{
Dorothy P. Schafer and Beth Stevens
}

Department of Neurology, F.M. Kirby Neurobiology Center, Boston Children's Hospital, Harvard Medical School, Boston, Massachusetts 02115

Correspondence: beth.stevens@childrens.harvard.edu

The nervous system comprises a remarkably diverse and complex network of different cell types, which must communicate with one another with speed, reliability, and precision. Thus, the developmental patterning and maintenance of these cell populations and their connections with one another pose a rather formidable task. Emerging data implicate microglia, the resident myeloid-derived cells of the central nervous system (CNS), in the spatial patterning and synaptic wiring throughout the healthy, developing, and adult CNS. Importantly, new tools to specifically manipulate microglia function have revealed that these cellular functions translate, on a systems level, to effects on overall behavior. In this review, we give a historical perspective of work to identify microglia function in the healthy CNS and highlight exciting new work in the field that has identified roles for these cells in CNS development, maintenance, and plasticity.

\begin{abstract}
M icroglia are one of the most enigmatic and understudied populations in the brain. Until recently, most of what was known about their function has been associated with their rapid and robust responses to disease and injury (Ransohoff and Perry 2009; Graeber 2010; Ransohoff and Cardona 2010). The idea that microglia could be performing normal, homeostatic functions is a relatively new concept, galvanized by pioneering in vivo imaging studies, which revealed that the processes of "resting" microglia are highly motile in the intact, healthy adult brain (Davalos et al. 2005; Nimmerjahn et al. 2005). Remarkably, it is estimated that these microglial processes survey the entire brain parenchyma within a matter of hours, raising many
\end{abstract}

questions about the significance of this immune surveillance system.

Since these initial findings, there has been a surge in the field to examine functional roles of microglia in the healthy central nervous system (CNS), with a primary focus on postnatal development. This focus was, to a large extent, incited by a landmark fate-mapping study in the mouse showing that microglia develop from primitive myeloid progenitors in the embryonic yolk sac and begin to colonize the brain during early embryonic development (approximately embryonic day 9.5 [ $\sim$ E9.5] in the mouse) (Ginhoux et al. 2010). Given this early colonization, microglia are poised to play important roles in shaping the developing CNS and contributing

Editors: Ben A. Barres, Marc R. Freeman, and Beth Stevens

Additional Perspectives on Glia available at www.cshperspectives.org

Copyright (C) 2015 Cold Spring Harbor Laboratory Press; all rights reserved; doi: 10.1101/cshperspect.a020545

Cite this article as Cold Spring Harb Perspect Biol 2015;7:a020545 
to overall nervous system function. Indeed, recent work has shown that microglia in the developing CNS can physically interact with neuronal soma and synapses in response to changes in neural activity, and data implicate microglia in many functions required to build and wire the developing CNS ranging from neurogenesis to synaptic pruning (Tremblay 2011; Tremblay et al. 2011; Kettenmann et al. 2013; Schafer et al. 2013; Wake et al. 2013; Salter and Beggs 2014). Furthermore, emerging work in the juvenile and adult reveal that these interactions and functions observed in the postnatal brain occur more broadly to affect plasticity over the life span of the animal, ultimately affecting behavior.

In this chapter, we review the latest findings in the field on microglia function in CNS development and plasticity. Our goal is to give a comprehensive and critical perspective of this relatively new area of research and highlight new questions. Furthermore, we discuss novel strategies to manipulate microglia function that will contribute to our understanding of these cells in the healthy nervous system and, ultimately, help to identify mechanisms of disease.

\section{SPATIAL PATTERNING IN THE DEVELOPING AND MATURE CNS}

In the context of CNS disease and injury, microglia are appreciated as "professional" phagocytes, known for their rapid and efficient ability to clear dead or dying cells and cellular debris (Wyss-Coray and Mucke 2002; Napoli and Neumann 2009; Ransohoff and Perry 2009; Ransohoff and Cardona 2010; Kettenmann et al. 2011; Sierra et al. 2013). Furthermore, microglia produce many factors that are known to actively trigger neuronal apoptosis, including tumor necrosis factor $\alpha$ (TNF- $\alpha$ ), reactive oxygen species, glutamate, etc. (Bessis et al. 2007). Thus, microglia not only play a role in dead cell clearance, but they may also play a more active role in initiating cell death or driving the cell death program in cells that are already rendered vulnerable/damaged. Consistent with this idea, recent work has shown in a range of disease states (glioma, brain ischemia, Alzheimer's disease, etc.) that microglia have the capacity to phagocytose live cells, including viable but stressed neurons, via a number of different microglial phagocytic signaling pathways (e.g., TREM2, MERTK, and MFG-E8) (Fig. 1C, top) (Brown and Neher 2014). Concomitant to this cytotoxic potential, microglia produce trophic, mitogenic, and antiinflammatory factors (Bessis et al. 2007; Pollard 2009). As a result, microglia are poised to play many diverse roles in patterning and maintaining the intricate and diverse cell populations that comprise the CNS. The following section reviews studies demonstrating a role for microglia in regulating CNS cell numbers during development and in adulthood.

\section{Regulation of Cell Death}

Essential to the development and spatial patterning of all organ systems is programmed cell death (PCD), a process by which many cells undergo apoptosis to achieve the cellular architecture characteristic of the mature system (Vaux and Korsmeyer 1999). When this process is absent or dysfunctional, a broad spectrum of developmental abnormalities and diseases can occur (Meier et al. 2000). Given its diverse and complex cell populations, the nervous system is particularly reliant on PCD and, thus, a model system for studying the process (Oppenheim 1991; Yeo and Gautier 2004; Rogulja-Ortmann et al. 2007). Indeed, during vertebrate development, $\sim 50 \%$ of neurons born must undergo PCD and the corpses must be cleared, a massive and necessary task to maintain CNS homeostasis. In addition, the importance of this process is further emphasized given that it is highly conserved across vertebrates and invertebrate species (Sulston and Horvitz 1977; Abrams et al. 1993; Bangs and White 2000).

The best-characterized role for microglia in PCD is their large capacity to phagocytose dead cell corpses during development (Fig. 1, top). One of the first descriptions of microglia carrying out this phenomenon was in the postnatal rat cerebral cortex, where, during the first week of rat postnatal development, a large amount of neuronal cell death occurs, particularly in the subplate and layers II/III (Ferrer et al. 1990). During this time, globular, vacuolated phago- 


\section{A Prodeath}

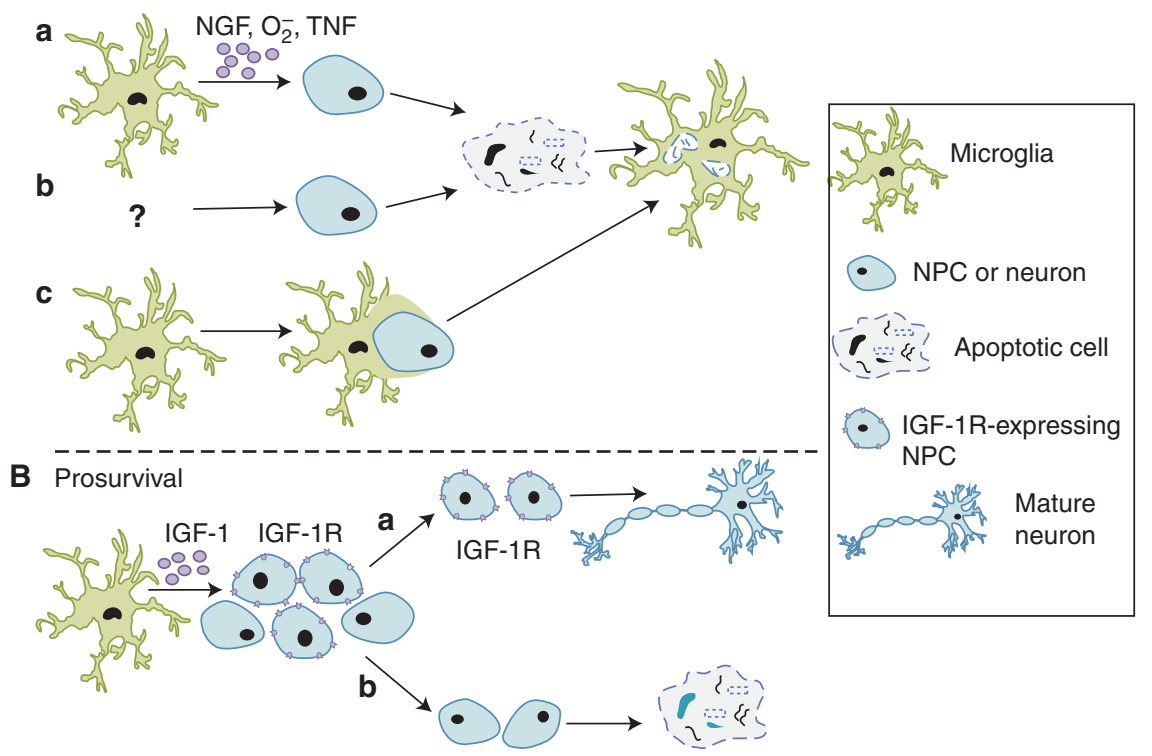

Figure 1. Mechanisms involved in microglia-mediated spatial patterning of neurons. $(A)$ The role of microglia in programmed cell death. (a) Microglia can initiate the cell death program through a variety of soluble (e.g., nerve growth factor [NGF], $\mathrm{O}_{2}^{-}$, and tumor necrosis factor [TNF]) and membrane-bound (e.g., CD11b and DAP12) factors followed by phagocytosis. (b) Alternatively, apoptosis of neurons or neural precursor cells (NPCs) is induced by unknown mechanisms followed by microglia-mediated phagocytosis of debris. (c) "Phagoptosis" has been described in injury/disease paradigms known to induce inflammation (Brown and Neher 2014) in which microglia actively engulf live cells. Evidence suggests that something similar may be happening in the healthy developing and adult central nervous system (CNS). (B) Microglia can also promote survival of NPCs in the developing CNS. One mechanism identified was insulin-like growth factor (IGF)-1, a soluble factor made and released by microglia, which is believed to bind IGF-1R receptors expressed by a subset of NPCs. It is speculated that those NPCs expressing the receptor survive $(a)$, whereas those that do not express the receptor undergo apoptosis $(b)$.

cytes, which are now assumed to be resident microglial cells, were found in increased numbers and had engulfed dead cells throughout the cortical and subplate regions. Since these original observations, microglia have been shown to phagocytose dead cells throughout the healthy, developing CNS (Bessis et al. 2007; Sierra et al. 2013). However, the mechanisms underlying these phagocytic events have remained unclear. Recent work in other model organisms may offer insight. For example, in Drosophila, glial cells, albeit not microglia, engulf dead cell corpses and axons through a Draper/dCED-6dependent signaling pathway, a pathway previously found in Caenorhabditis elegans (Zhou et al. 2001). In addition, microglia engulf apoptotic neurons in developing zebrafish via an- other pathway, the v0-ATPase al subunit (Logan and Freeman 2007; Peri and NussleinVolhard 2008; Kurant 2011; Schafer and Stevens 2013). It remains to be determined whether the same or similar mechanisms are involved in PCD in the mammalian CNS. Furthermore, although studies show that microglia play an important role in the removal of large amounts of cellular debris produced by PCD, in itself a daunting task, it was unclear whether microglia were playing a role in the initiation of apoptotic events. Recent work suggests a more active role by which microglia initiate or, perhaps, propagate the cell death program before phagocytosis (Fig. 1A,C, top).

The concept of phagocytes initiating cell death before phagocytosis was first conceived 
in the late 1800s by Elie Metchnikoff, who first described phagocytosis, and early work showed that peripheral tissue macrophages could perform such a function in developmental tissue remodeling (Aliprantis et al. 1996). For example, a study in the developing rodent retina showed that, following genetic depletion of eye and peritoneal macrophage subtypes, there was a persistence of ocular tissues that are normally developmentally transient, the hyaloid vasculature and pupillary membrane (Lang and Bishop 1993). Since this time, microglia, the resident CNS myeloid-derived cells, have been shown to perform similar roles. The first evidence was in the chick retina, where optic cups grown in the absence of microglia resulted in a nearly threefold reduction in retinal cell death as compared with optic cups grown in the presence of microglia (Frade and Barde 1998). Furthermore, when purified microglia were added back to the optic cup cultures, retinal cell death was increased. The molecular mechanism underlying this effect was identified as microglial-derived nerve growth factor (NGF). NGF expression was largely restricted to microglia during this developmental window, and retinal PCD was blocked with NGF antibodies. It was proposed that microglial-derived NGF initiates cell death when it binds the neurotrophin receptor $\mathrm{p} 75$ ( $\mathrm{p} 75^{\mathrm{NTR}}$ ), which is expressed by nearly all cells in the chick retina. Using a similar in vitro approach, microglia were also shown to initiate the PCD of Purkinje neurons in the developing mouse cerebellum and motoneurons in the developing rat spinal cord (Marin-Teva et al. 2004; Sedel et al. 2004). Using cerebellar slices, ablation of microglia using clorodronate-filled liposomes resulted in a reduction in Purkinje neuron PCD (Marin-Teva et al. 2004). This cytotoxic effect was mediated by microglial respiratory bursts, which produce superoxide ions $\left(\mathrm{O}_{2}^{-}\right)$. However, the investigators also observed in vivo that $>60 \%$ of Purkinje neurons that were contacted by microglial processes, but not yet phagocytosed, were already expressing molecules associated with damage/PCD (i.e., activated caspase$3)$. These data suggest a role for microglia in driving the cell death program in neurons that are already rendered vulnerable, a concept that has been suggested in other model organisms (C. elegans and Drosophila) where dying, but not yet dead, cells are engulfed by neighboring cells, including glia (Logan and Freeman 2007; Kinet and Shaham 2014). Similarly, using cultured spinal cord explants from developing rat embryos, microglial ablation, or blocking of microglial-derived TNF- $\alpha$ signaling resulted in a decrease in motoneuron PCD (Sedel et al. 2004). However, microglial TNF- $\alpha$ expression within the spinal cord was transient and downregulated before the cell death, data suggesting that microglial-derived TNF- $\alpha$ may not directly induce cell death but rather render motoneurons more competent to die via other, yet-to-be-identified, neurotrophic factor-mediated mechanisms.

Although intriguing and consistent with macrophage studies, these initial studies suggesting that a more active role for microglia in PCD were all in vitro or ex vivo, which, in themselves, induce injury during preparation. To better address this question under more physiological conditions, more recent studies have taken advantage of strategies to genetically and/or pharmacologically manipulate microglia in vivo. One study assessed PCD in the neonatal hippocampus, where microglia were found to associate with neurons undergoing apoptosis (Wakselman et al. 2008). To determine an underlying mechanism, the investigators assessed mice deficient in CD11b (CD11b $\mathrm{b}^{-/-}$), a surface receptor integrin, and mice with loss of function in DAP12 (DAP12 $\left.{ }^{\mathrm{KI}}\right)$, a transmembrane signal transduction adaptor molecule. These two molecules are expressed by peripheral immune cells, including macrophages, where they carry out effector functions such as cell adhesion and phagocytosis (Mocsai et al. 2006). Importantly, in the context of normal development, these receptors are almost exclusively expressed by microglia in the CNS. In CD $11 b^{-/-}$and DAP $12^{\mathrm{KI}}$ mice, there was a significant, although not complete, reduction in neuronal apoptosis. In addition, the investigators provided evidence that $\mathrm{CD} 11 \mathrm{~b}$ and DAP12 regulate the production of $\mathrm{O}_{2}^{-}$by microglia, data consistent with earlier in vitro work in the cerebellum (Marin-Teva et al. 2004). However, future work is necessary 
to show whether microglia initiate neuronal PCD in other CNS regions in vivo and whether CD11b, DAP12, and/or $\mathrm{O}_{2}^{-}$are involved. Furthermore, neuronal PCD, albeit reduced, was still observed in the hippocampus in DAP $12^{\mathrm{KI}}$ mice (Wakselman et al. 2008), and neurons in the cerebellum appeared to already express markers of cell death in the cerebellum before engulfment (Marin-Teva et al. 2004). Thus, although microglia may play a role in the initiation of cell death in a subset of neurons, they may also be involved in facilitating the progression of cell death in another subset that are already rendered vulnerable by other mechanisms. The latter is particularly intriguing given that, in an otherwise healthy milieu, the precise timing of PCD is critical. Microglia may offer a mechanism by which this cell death timing is regulated. In addition, these data also suggest that other molecular and/or cellular mechanisms (e.g., astrocyte-mediated phagocytosis) must also be involved, which are critical areas of investigation going forward.

To address whether microglia play a more global role in regulating neuronal cell numbers during brain development, a more recent study assessed microglial interactions with neurons during neurogenesis in the developing cerebral cortex of prenatal and postnatal macaques and rats (Cunningham et al. 2013). In both species, microglia-colonized cortical proliferative zones and phagocytosed neural precursor cells (NPCs) as neurogenesis was nearing completion. In addition to showing correlative immunolocalization, the investigators used in vitro and in vivo pharmacological strategies in mice to manipulate microglia. Specifically, microglia were either inactivated (e.g., reductions in inflammatory molecule production, phagocytic capacity, etc.) using broad-spectrum tetracyclines (minocycline or doxycycline), or eliminated by injection of liposomal clodronate into the lateral ventricles in utero. Conversely, the investigators pharmacologically "activated" microglia (e.g., increases in inflammatory molecule production, phagocytic capacity, etc.) in utero using a model of maternal immune activation in which pregnant dams are injected with bacterial lipopolysaccharide (LPS). When microglia were pharmacologically "inactivated" or eliminated in utero, there was an increase in NPCs later in development (embryonic day 19 [E19] and postnatal day 2 [P2]). Furthermore, "activating" microglia with LPS resulted in a decrease in NPC number at E19 and P2, although the effects were substantially less compared with "inactivation" experiments. These data suggest that microglia may actively regulate NPC numbers in the developing brain by inducing apoptosis of NPCs followed by phagocytosis (Fig. 1A, top). The possibility still exists that this could be a neurogenic effect, which is consistent with another recent study in which doxycycline in adult mice induced an increase in hippocampal neurogenesis (discussed below) (Sultan et al. 2013). Another important aspect to consider is that the pharmacological agents used are relatively nonspecific to microglia and affect several other cell types outside and inside the CNS (Smilack 1999; Hagberg and Mallard 2005; Bilbo et al. 2006; Buller et al. 2009; Meyer et al. 2009). Thus, molecular mechanisms must be identified and targeted using approaches to specifically manipulate microglia versus other cell types.

In addition to development, microglia have now been implicated in PCD that occurs throughout the life of an organism. This work has centered around the hippocampus, where neurogenesis occurs in the subgranular zone of the dentate gyrus during adulthood. Although a small subset of these newly born neurons incorporate into the circuitry, the remaining cells are believed to die (Song et al. 2012). Using a combination of immunohistochemistry, transgenic green fluorescent protein (GFP) - expressing mice, and bromodeoxyuridine labeling, it was shown that most newly born neurons in the subgranular zone of 1-mo-old mice die within the first $4 \mathrm{~d}$ of birth (56\% of newborn cells; 400 cells/h) and phenotypically "resting" microglia appear to efficiently phagocytose these apoptotic cell bodies ( $>90 \%$ of apoptotic cells in the subgranular zone) within this 4 -d period (Sierra et al. 2010). Furthermore, microglia were shown to regulate their phagocytic capacity that mirrored changes in neurogenesis and cell death induced by age (decrease) or LPS- 
mediated inflammation (increase). Although this study demonstrated a role for microglia in the elimination of apoptotic NPCs, another study has shown that NPCs, themselves, can phagocytose dying cells during adult hippocampal neurogenesis (Lu et al. 2011). Thus, it appears that microglia and NPCs may be working together to eliminate apoptotic NPCs. In addition, unlike the developing CNS, it remains unclear whether microglia and/or neighboring NPCs are involved in inducing apoptosis in these newly born neurons in the adult hippocampus. Evidence that apoptotic neurons exist in the absence of microglial or NPC contact suggest that this may be a neuron-autonomous event followed by phagocytosis (Fig. 1B, top). However, there is some evidence in the adult mouse dentate gyrus that microglia appear to infiltrate small cytoplasmic openings of granule cells before cell death and that these microglial processes closely appose the nuclei of granule cells, data suggesting a more active role in initiating or contributing to progression of the death program (Ribak et al. 2009).

Regulation of Cell Survival, Proliferation, and Differentiation

Microglia have also been implicated in spatial patterning of the developing and adult CNS by promoting cell survival, proliferation, and/or differentiation (Fig. 1, bottom). Some of the first lines of evidence for this were in vitro studies in which microglia-conditioned media was added to neuronal cultures, resulting in enhanced progenitor cell proliferation and enhanced neuron survival and/or maturation (Nagata et al. 1993; Chamak et al. 1994; Morgan et al. 2004). However, other recent work has shown that culturing NPCs isolated from cortices that lack microglia $\left(\right.$ PU. $1^{-/-}$) had no effect on neuron survival or neurogenesis but rather resulted in decreases in neural progenitor cell proliferation and astrogenesis, effects that were rescued by adding wild-type (WT) microglia back to the cultures (Antony et al. 2011). Conversely, another study cultured NPCs from adult hippocampus and observed a reduction in progenitor cell proliferation in the presence of microglia (Gebara et al.
2013). In the same study, the investigators used models of enhanced (exercise) or impaired (aging) hippocampal neurogenesis to show an inverse correlation between the number of microglia and the number of progenitor cells in fixed tissue. There are several explanations for these disparate results. The most plausible explanations are differences in culture conditions, ages of mice used for the study, and/or regionspecific effects. Furthermore, although it is clear from all of these studies that microglia have the capacity to regulate progenitor cell numbers, in vivo strategies and careful developmental analyses are necessary.

A more recent study has addressed whether microglia can promote neuron cell survival in vivo in the developing mouse cortex (Fig. 1, bottom) (Ueno et al. 2013). The investigators showed that, between P3 and P5, "inactivating" microglia with minocycline or ablating microglia by injecting diphtheria toxin into mice expressing the diphtheria toxin receptor under the control of the $\mathrm{CD} 11 \mathrm{~b}$ promoter resulted in an increase in the number of apoptotic neurons specifically in layer V of the cerebral cortex. Furthermore, microglia still appeared to engulf apoptotic debris after minocycline treatment, suggesting that microglial phagocytic capacity is not inhibited. In contrast, the data suggest that microglia provide trophic support for neurons in the early postnatal CNS. Consistent with this idea, the investigators show that mice deficient in the fractalkine receptor (CX3CR1), which is expressed almost exclusively by microglia in the context of the postnatal CNS, have a similar reduction in layer $\mathrm{V}$ neurons. Furthermore, CX3CR1 knockout mice had a reduction in free insulin-like growth factor 1 (IGF-1) and an increase in IGF-1-binding proteins, data suggesting that IGF-1 may be a factor downstream from CX3CR1 that promotes neuron survival. When in vitro and in vivo approaches were used to block IGF signaling (pharmacology and small interfering RNA), there was a significant increase in cortical neuron cell death. However, none of the strategies used by these investigators were completely specific to microglia, as other cell types, particularly outside the CNS, express CX3CR1 and IGF-1. Future work using Cre-lox 
Microglia in Development and Plasticity

technology to gain better cell specificity is necessary.

Taken together, the data demonstrate a role for microglia in spatial patterning of nervous system tissue by clearing apoptotic cells (neurons and neural progenitors). In addition, experiments also suggest a role for microglia in either initiating the cell death program or progressing cell death in a neuron previously rendered vulnerable. At the same time, there is also new evidence that microglia can also promote neuron and NPC survival and/or proliferation. Given that these seemingly disparate functions (pro-cell death and pro-survival/proliferation) occur during very similar time frames, it remains unclear how microglia carry out these functions simultaneously and raises the intriguing possibility that microglia are a heterogeneous cell population with several different subtypes of cells performing vastly different functions. In addition, although work using ablation techniques to get rid of microglia during specific developmental time points has shown some modest effects on cell numbers, ablation of microglia in the adult brain has shown no significant effect (Parkhurst et al. 2013; Elmore et al. 2014). Several different explanations could account for this, such as the importance of context/timing; the developing CNS may be particularly sensitive to these manipulations. In addition, there may be overlapping functions with astrocytes, which can also phagocytose. In fact, it has been shown that these cells can perform a similar role as microglia in the context of synaptic pruning (Chung et al. 2013). Future work using more specific in vivo strategies to manipulate microglia is necessary. Pharmacological strategies (LPS, minocycline, and doxycycline) are nonspecific, with effects on many cell types. Furthermore, although data are promising in mice deficient in CD11b, DAP12, CX3CR1, and IGF-1 signaling, other cell types also express these molecules and are, thus, affected by genetic targeting. Recently, $C \times 3 c r 1^{\text {creER }}$ mice, in which creER is expressed under the control of the fractalkine receptor (CX3CR1), are an exciting new tool that will enable the analysis of microgliaspecific effects (Goldmann et al. 2013; Parkhurst et al. 2013; Yona et al. 2013).

\section{SYNAPTIC WIRING IN THE CNS}

Similar to the excess of neurons born early in development, an excess of synaptic contacts are formed initially, many of which are later pruned away by phagocytic microglia during synapse elimination, a process critical for precise synaptic connectivity (Fig. 2) (Purves and Lichtman 1980; Lichtman and Colman 2000; Kano and Hashimoto 2009). In addition, new research suggests that microglia can also influence brain wiring by regulating the number, maturation, and plasticity of synapses in development and throughout the life span. The following section reviews these findings.

\section{Activity-Dependent Interactions with Synapses}

One of the first clues that suggested a role for microglia in synaptic pruning was the observation that process-bearing, phagocytic microglia were enriched in brain regions undergoing active synaptic remodeling, including cerebellum, hippocampus, and the visual system (Perry et al. 1985; Milligan et al. 1991; Dalmau et al. 1998; Maslinska et al. 1998; Wierzba-Bobrowicz et al. 1998; Schafer et al. 2012; Schwarz et al. 2012). However, it remained unclear if these cells were performing functions at developing synapses. Indeed, recent in vivo live imaging studies in the adult and juvenile mouse cortex show that microglia processes dynamically interact with developing synapses and can detect local changes in neuronal activity (Tremblay et al. 2010; Wake et al. 2013). For example, in layers II/III of the adult somatosensory and visual cortex, microglial processes briefly contacted synaptic elements at a rate of $\sim 1$ synapse/h (Wake et al. 2013). Interestingly, this study also showed that microglia-synapse contact was reduced when neuronal activity was blocked by tetrodotoxin (TTX), enucleation of an eye, or lowering the temperature. However, it remains to be determined whether these activity-dependent interactions influenced synaptic remodeling.

To examine activity-dependent microgliasynapse interactions under more physiological conditions, Tremblay and colleagues combined 
D.P. Schafer and B. Stevens

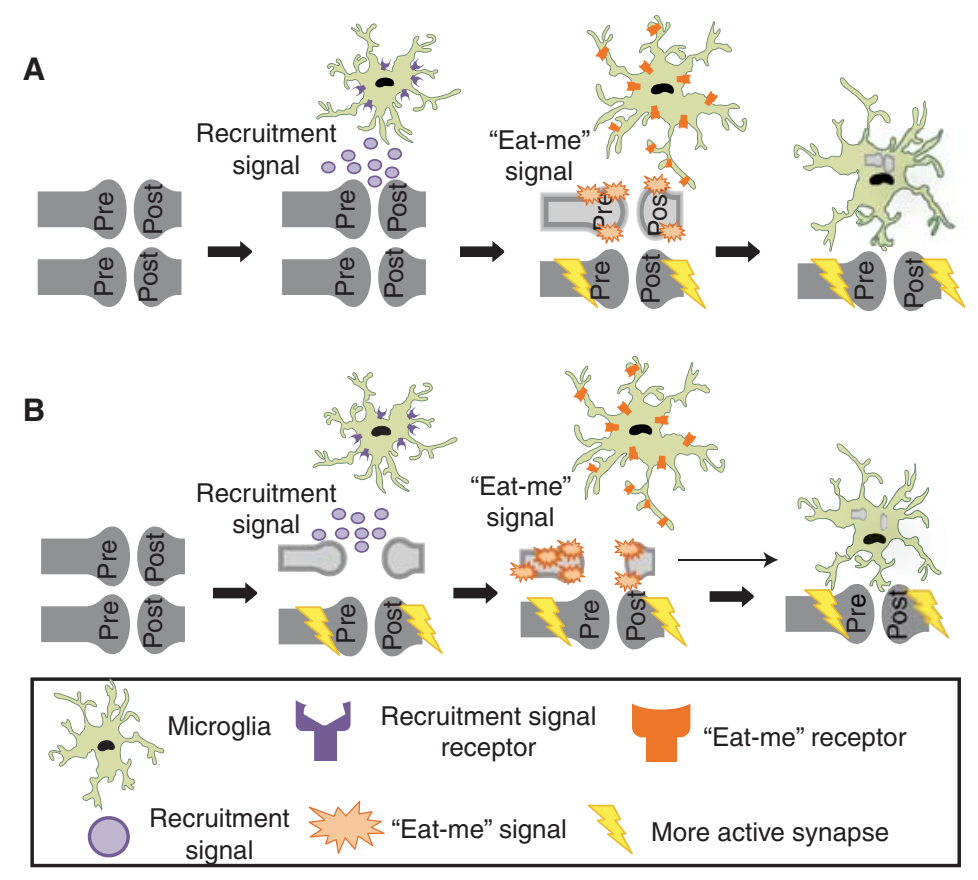

Figure 2. The role of microglia in developmental, activity-dependent synaptic remodeling. $(A)$ A model in which microglia selectively engulf a subset of less active, intact synapses. Data suggest that a signal (e.g., fractalkine) recruits microglia to remodeling synapses. Those synapses that are less active (light gray) are molecularly "tagged" with "eat-me" signals (e.g., complement). Microglia, expressing receptors for "eat-me" signals (e.g., CR3), actively select and phagocytose intact synaptic components. (B) A model whereby neurons autonomously begin to prune (retract and/or fragment) before engulfment by microglia. Data suggest that a recruitment signal (e.g., fractalkine) recruits microglia to remodeling synapses. Those synapses that are less active (light gray) begin to autonomously retract and/or fragment. These pruning synapses are subsequently "tagged" with "eat-me" signals (e.g., complement), followed by engulfment by microglia, which express receptors for "eat-me" signals (e.g., CR3).

high-resolution three-dimensional serial electron microscopy (EM) with two-photon live imaging during the critical period in the juvenile mouse primary visual cortex (V1) (Tremblay et al. 2010), a region and time period where heightened structural and functional plasticity is known to occur (Majewska and Sur 2003; Bence and Levelt 2005; Hooks and Chen 2007). During the critical period within V1, microglia appeared to contact synaptic elements $(\sim 1$ synaptic element per $40 \mathrm{~min})$, and spines, in particular, appeared to change size upon microglia contact. Interestingly, many of the spines contacted by microglia tended to be smaller and were often no longer present at later imaging sessions, data suggesting microglia may be playing a role in the elimination of these spines. To address how activity may be involved, the investigators also visualized microglia-synapse interactions following a dark adaptation paradigm known to elicit robust synaptic remodeling (Mower et al. 1983; Philpot et al. 2001; Viegi et al. 2002; Tropea et al. 2010). Using this paradigm, in dark-adapted mice or dark-adapted mice re-exposed to light, live imaging revealed that microglia changed their motility and interactions with spines as compared with lightreared control animals. Furthermore, EM analysis revealed that microglia appeared to more frequently contact synaptic elements and had more phagocytic inclusions as compared with light-reared control animals. These phagocytic inclusions were speculated to be synaptic elements, suggesting a role for microglia in experi- 
ence- dependent synaptic remodeling in the mature brain. It remains to be determined if these highly dynamic and activity-dependent interactions have functional significance during brain wiring.

To test the hypothesis that microglia phagocytose excess or exuberant synaptic connections during postnatal development, Schafer et al. took advantage of the mouse retinogeniculate system, a visual pathway and classic model system in which to study activity-dependent synapse elimination (Schafer et al. 2012). In this system postsynaptic thalamic relay neurons within the dorsal lateral geniculate nucleus (dLGN) are initially innervated by multiple weak retinal ganglion cell inputs originating from the retina. A subset of these presynaptic inputs are later eliminated, while the remaining inputs are maintained and strengthened (Chen and Regehr 2000; Hooks and Chen 2006; Huberman 2007; Huberman et al. 2008). Using this system, the investigators observed microglial processes closely apposed to presynaptic inputs undergoing remodeling within the dLGN, data consistent with previous live imaging and EM data (Tremblay et al. 2010). Subsequently, a novel in vivo assay was developed in mice to determine if microglia were engulfing inputs (Schafer et al. 2012, 2014). In this engulfment assay, presynaptic inputs within the dLGN are fluorescently labeled by intraocular injection of anterograde dyes that are highly stable and resistant to lysosomal degradation (i.e., cholera toxin $\beta$ subunit conjugated to Alexa dyes). Furthermore, this assay allows one to distinguish inputs from the left versus right eye by injecting dye tracers with different excitation and emission spectra (e.g., cholera toxin $\beta$ subunit conjugated to Alexa 594 and Alexa 647, respectively). During the height of presynaptic input remodeling (P5 in the mouse), microglia contained presynaptic inputs within their processes and within lysosomal compartments. Furthermore, EM analysis revealed engulfed retinal ganglion cell axonal terminals throughout the dLGN.

Do microglia engulf specific synapses or do they act as the cleanup crew that remove synaptic debris (Fig. 2)? Synaptic pruning is believed to result from competition between neighbor- ing axons for postsynaptic territory based on differences in patterns or levels of activity, such that weaker or less active synapses lose territory while stronger or more active synaptic inputs are elaborated and strengthened (Katz and Shatz 1996; Sanes and Lichtman 1999; Hua and Smith 2004). Recent data in the retinogeniculate system support the hypothesis that microglia preferentially engulf less active synapses during activity-dependent synaptic competition. For example, manipulation of retinal activity with TTX to block activity or forskolin, a cAMP analog that increases retinal activity, revealed that microglia preferentially engulf presynaptic inputs in the dLGN from the less active eye (Schafer et al. 2012). Together these data reveal that microglia, indeed, engulf synapses during developmental synaptic pruning in an activitydependent manner. These data now raise questions about the underlying mechanisms. How do microglia know which synapses to target? How do certain synapses become destined for elimination over others? Are synapses, indeed, intact at the time of engulfment (Fig. 2)?

\section{Functional Consequences of Microglia-} Synapse Interactions: Synaptic Pruning

One molecular pathway that has been proposed to mediate microglia-synapse interactions and synaptic pruning is the classical complement cascade (Stevens et al. 2007; Schafer and Stevens 2010; Alexander et al. 2012). Classical complement cascade proteins C1q and C3 are localized to synaptic compartments and mediate synaptic pruning in the developing retinogeniculate system (Stevens et al. 2007). In the innate immune system, C1q and/or C3 bind cellular material, inducing its removal by several mechanisms, including phagocytic pathways (Lambris and Tsokos 1986; Gasque 2004; van Lookeren Campagne et al. 2007) Together, these findings raised the hypothesis that complement $\mathrm{C} 1 \mathrm{q}$ and $\mathrm{C} 3$ target synapses for elimination by microglia, which, in the context of the healthy postnatal brain, are the only cells to express the high-affinity receptor for C3, complement receptor 3 (CR3; Cd11b) (Schafer et al. 2012). Consistent with this hypothesis, C3 protein is highly ex- 
pressed and localized to synapses in the postnatal dLGN, and CR3 is expressed by microglia at particularly high levels during the peak of microglia-mediated synaptic engulfment (P5). C3 and CR3 knockout mice have reduced engulfment of presynaptic retinal inputs and a sustained deficit in eye-specific segregation that phenocopied C1q and C3 knockout mice (Schafer et al. 2012), implicating phagocytic microglia as a key downstream cellular mediator of complement-dependent synapse elimination. Importantly, genetic disruption of CR3/C3 signaling resulted in sustained deficits in synapse number and synaptic connectivity. These findings show that microglia-synapse interactions, indeed, have functional consequences on synaptic pruning that are sustained. Furthermore, the data provide some insight into how synapses might be molecularly targeted for elimination by microglia (Fig. 2). However, it is not yet known if complement proteins are localized to specific (i.e., less active/weaker) synapses and whether changes in neuronal activity impact this process. Finally, the identities of specific receptors for complement at the synapse remain elusive. A recent in vitro study suggests that terminal sugar residues in the extracellular matrix of glycoproteins surrounding neurons mediate Clq binding to neurites (Linnartz et al. 2012). In future work, it will be interesting to test whether sialic acid residues in axons play a similar role in vivo and whether the complement cascade mediates synapse elimination in the developing hippocampus and other brain regions.

In addition to complement, recent data have also implicated microglia in synaptic remodeling in the hippocampus via a CX3CR1-dependent mechanism (Tremblay et al. 2010; Paolicelli et al.2011). Paolicelli and colleagues showed that mice deficient in CX3CR1 (CX3CR1 knockouts) exhibited a transient increase in spine density in postnatal weeks 2 and 3 in the hippocampus, and, similar to the case in the developing visual system, high-resolution imaging and EM revealed a concomitant increase in postsynaptic density protein 95 (PSD95)-positive immunoreactivity within microglia (Paolicelli et al. 2011). Interestingly, there were significantly fewer microglia detected in the postnatal hip- pocampus of CX3CR1 knockout mice, and these abnormalities in microglia number and synapse density returned to normal levels by adulthood. These data suggest that fractalkine signaling regulates microglia number and/or recruitment to synaptic sites in the early postnatal brain (Fig. 2). Another study showed different defects in synaptic function in the mature hippocampus of CX3CR1 knockout mice, raising the possibility that fractalkine signaling may play different roles depending on the context (Rogers et al. 2011). In this case, long-term potentiation induction was reduced in organotypic hippocampal slices prepared from adult CX3CR1 knockout mice as compared with WT littermates (Rogers et al. 2011). Importantly, these deficits were coincident with impairments in learning and memory as assessed by Morris water maze and contextual and cued fear conditioning.

It is not yet known whether microglia engulf synapses as part of an activity-dependent developmental pruning process in the hippocampus, as was demonstrated in the visual system. Furthermore, it remains unclear whether fractalkine and complement systems are working cooperatively to contribute to synaptic pruning. There is also an open question as to whether these are, indeed, microglia-specific effects, as many immune cells, albeit localized to the periphery and not the healthy CNS, express these receptors. Along these same lines, it has also recently been shown that, similar to microglia, astrocytes in the retinogeniculate system can also contribute to synaptic pruning by phagocytosing developing synapses in an activity-dependent manner (Chung et al. 2013). These data suggest that these two phagocytic cell populations could be working cooperatively to achieve proper brain wiring. Experiments designed to address these questions will be important areas of future investigation (Ransohoff and Stevens 2011).

\section{Functional Consequences of Microglia- Synapse Interactions: Modulation of \\ Synapse Maturation and Function}

Although synapse formation and pruning are key features of circuit development, so too are the function and maturation of the synapses that 
remain. Electrophysiological studies performed in CX3CR1 knockout mice suggest that microglia also regulate synapse maturation and long-range synaptic connectivity. In the healthy, developing hippocampus, Paolicelli et al. (2011) showed that the spontaneous excitatory postsynaptic current (EPSC)/miniature EPSC (sEPSC/ mEPSC) amplitude ratio, which normally increases during development, was diminished in the postnatal knockouts. Consistent with these data, postnatal CX3CR1 knockout mice also exhibited a transient increase in spine density and enhanced hippocampal long-term depression. In addition, susceptibility to druginduced seizures was reduced, consistent with the pattern normally observed in younger WT mice. Importantly, most of the effects observed in CX3CR1 knockout mice were transient, suggesting a developmental delay in hippocampal synaptic connectivity in knockout mice. In a recent study by the same group, the functional maturation and connectivity of synaptic networks was further investigated in CX3CR1 knockout mice (Zhan et al. 2014). Despite microglia and spine numbers in the hippocampus returning to control levels in young adult mice, the sEPSC/mEPSC ratio remained low in CX3CR1 knockout mice as compared with WT controls. EM revealed that this may be because of a failure of CA3 axons in knockout mice to form multisynapse boutons (i.e., axons forming synapses on more than one dendritic spine) in CA1. Consistent with abnormal connectivity, there was also a reduction in functional connectivity between the hippocampus and prefrontal cortex in CX3CR1 knockout mice, as assayed by the coherence of local field potentials and functional magnetic resonance imaging. Although it remains to be tested directly, it is speculated that abnormal synaptic pruning may underlie functional connectivity deficits in CX3CR1 knockout mice. Taken together, these findings suggest that transient developmental defects in microglia numbers and function can have sustained and broad consequences on synaptic maturation and connectivity.

Consistent with microglia playing a role in synapse maturation in the hippocampus, previous studies showed that maturation of hippo- campal synapses was altered in mice harboring a mutation in KARAP/DAP12, a transmembrane immune receptor expressed by developing microglia from birth (Tomasello et al. 1998, 2000; Roumier et al. 2004, 2008; Hamerman et al. 2005; Turnbull et al. 2005). Hippocampal slices from mice deficient in KARAP/DAP12 function displayed a subunit composition of $N$-methyl-D-aspartate (NMDA) receptors and calcium permeability status of AMPA receptors that are both characteristic of immature synapses and appear to have enhanced long-term potentiation (Roumier et al. 2004). Microglia express an array of ion channels and receptors that can be stimulated by neurotransmitters and activity-dependent signals, such as ATP and glutamate. Thus, in addition to responding to neuronal activity, microglia also have the potential to modulate basal glutamatergic and GABAergic synaptic transmission in the healthy CNS (Tsuda et al. 2003; Coull et al. 2005; Pascual et al. 2011). Altogether, these studies suggest that microglia play a crucial role in regulating synapse maturation, plasticity, and function in the healthy brain.

\section{ROLES IN MODULATING BEHAVIOR}

Given the exciting new data that microglia play important functions in regulating cell numbers and synapse density in the developing and mature CNS, it is conceivable that these functions translate to regulation of overall behavior. In the following section, we review emerging work that suggests that microglia contribute to behavioral abnormalities associated with neuropsychiatric disorders. Consistent with this idea, we also discuss recent findings that microglia contribute to behavior under healthy, steady-state conditions.

\section{Behavioral Effects Associated with Neuropsychiatric Disorders}

Some of the most compelling data suggesting a role for microglia in regulating behavior has arisen from analysis of neuropsychiatric disorders such as autism spectrum disorder, obsessive-compulsive disorder, and schizophrenia. For example, there are observations that abnor- 
mal microglial cell activation exists along with deficits in synaptic connectivity in patients with these disorders (Arnold 1999; Belmonte et al. 2004; Vargas et al. 2005; Woo and Crowell 2005; Monji et al. 2009; Morgan et al. 2010; Melom and Littleton 2011; Waites and Garner 2011). At the same time, there are now several animal models of these neuropsychiatric disorders in which there appear to be roles for microglia in onset and/or progression of behavioral phenotypes (Bilbo and Schwarz 2012; Derecki et al. 2012a; Blank and Prinz 2013). For example, in mouse models of autism spectrum disorder (Mecp2 null) and obsessive-compulsive disorder (Hoxb null), transplantation of WT bone marrow into irradiated null hosts results in attenuation of behavioral phenotypes (Chen et al. 2010; Derecki et al. 2012b). In the case of the Mecp2 null, this attenuation was concomitant with the colonization of host CNS by bone marrow-derived myeloid cells with a microglia phenotype (Derecki et al. 2012b). Another example of microglial involvement in behavioral abnormalities associated with neuropsychiatric disorders is rodent models of maternal immune activation. In maternal immune activation, mice are subjected to early-life infection in utero and offspring develop several behavioral phenotypes associated with schizophrenia (e.g., deficits in prepulse inhibition and acoustic startle response and decreases in exploratory behavior and social interactions) and/or memory and learning loss, particularly if combined with a later-life stress or immune challenge (i.e., peripheral LPS administration) (Bilbo and Schwarz 2009; Meyer et al. 2009; Patterson 2009; Harvey and Boksa 2012). These behavioral phenotypes are accompanied by changes in microglia including activation state and numbers in a brain region-specific manner (Bilbo et al. 2005, 2007; Williamson et al. 2011; Giovanoli et al. 2013). These data provide evidence that microglia may be "primed" prenatally during early-life infection and that a subsequent challenge can significantly enhance their effects on later-life behavior. This has been further substantiated by showing that microglial-derived interleukin- $1 \beta$ is a primary mechanism by which deficits in hippocampal-dependent learning and memory are induced following in utero immune challenge followed by later-life stress (Williamson et al. 2011). Furthermore, a similar cytokine-mediated "priming" mechanism may also contribute to age-dependent memory loss associated with aging and neurodegenerative disease (Barrientos et al. 2006; Perry et al. 2007).

\section{Behavioral Effects in the Healthy CNS}

In addition to neuropsychiatric disorders, there is also new evidence that microglia can affect baseline behavior in the absence of disease. For example, increased numbers of activated microglia were observed in the preoptic nucleus of healthy male rats as compared to females (Lenz et al. 2013). When minocycline was administered to males, there was a decrease in activated microglia in males, which more closely resembled female microglia, and a coincident display of feminine behaviors. Likewise, if females were administered estradiol, which increased prostaglandin $\mathrm{E}_{2}$ and microglial activation, masculine behaviors were observed. This work suggests that microglia could be playing key roles in regulating sexual behavior. This concept is further substantiated by sexual dimorphisms that exist in microglial colonization and total numbers throughout the CNS (Schwarz and Bilbo 2012; Schwarz et al. 2012). More direct, genetic evidence that microglia could be playing roles in baseline behavior include work in CX3CR1-deficient mice, which have deficits in long-term potentiation accompanied by significant deficits in contextual fear learning and performance in the Morris water maze (Rogers et al. 2011). However, another study found the opposite result, with very little effect on behavioral performance (Maggi et al. 2009). This may be attributed to differences in paradigms used for behavioral measurements in the two studies.

A recent study provided more direct evidence for a role of microglia in regulating behavior using a strategy to manipulate gene expression specifically in microglia $\left(\mathrm{C} \times 3 \mathrm{cr}^{\mathrm{creER}}\right)$ (Parkhurst et al. 2013). This system takes advantage of the relatively low turnover rate of microglia versus other peripheral CX3CR1 ${ }^{+}$immune 
cells, which turn over regularly (within a week) during hematopoiesis. After tamoxifen treatment, peripheral cells that underwent recombination turned over within $1 \mathrm{wk}$, resulting in microglia-specific, Cre-mediated expression of genes (Goldmann et al. 2013; Parkhurst et al. 2013; Yona et al. 2013). Using these mice, microglia were depleted using a diphtheria toxin strategy, or brain-derived neurotrophic factor (BDNF) was specifically knocked out in microglia. In either case, the result was a significant deficit in performance on a rotarod as well as in a fear-conditioning paradigm. Furthermore, these effects were accompanied by a decrease in dendritic spine formation, specifically in the motor cortex. Although it is not yet clear how manipulation of BDNF in microglia impacts motor learning or synaptic function, this was the first evidence that manipulating a gene specifically in microglia had effects on synaptic structure and, ultimately, on behavior. In contrast, when another recent study pharmacologically depleted microglia from adult mice, no significant behavioral deficits were observed (Elmore et al. 2014). The discrepancies in these data may be explained in several ways, including that a critical period (before adulthood) may exist in which the rodent brain is particularly sensitive to microglial ablation. In addition, the behavioral measures used for the latter study were rather limited, and more extensive analyses may be necessary to observe differences following pharmacological ablation in the adult.

Taken together, the data demonstrate a critical function for microglia in regulating behavior, particularly if these cells are manipulated during development (postnatal through juvenile stages). In addition, recent publications have advanced the field significantly by providing genetic mouse models (Parkhurst et al. 2013; Yona et al. 2013). The use of these mice will be critical going forward to specifically manipulate microglia and understand their function in the healthy and diseased CNS.

\section{CONCLUDING REMARKS}

The idea that microglia, compared with other glial cell types, perform important functions in the healthy nervous system is a relatively new concept. This line of thinking was propagated by experiments that used live imaging to determine that microglial processes were highly motile, often contacting synapses, in the healthy, intact brain. Other work described microglia in close apposition to and/or phagocytosing dead/dying neurons, neural progenitor cells, and synapses. Consistent with these cellular interactions having a more functional role, pharmacological and more specific genetic strategies to target microglial phagocytic function result in significant deficits in developmental neuronal PCD and synaptic pruning. On a behavioral level, abnormal microglial activation has been observed in humans and mouse models of neuropsychiatric disorders. Furthermore, when WT, microglia-like cells are introduced into mouse models of these disorders, some behavioral deficits are attenuated. Despite these intriguing findings, it remains unclear how microglia contribute to behavioral phenotypes associated with these disorders. One idea is that there are abnormalities in microglia-synapse interactions during development. However, this remains to be tested. Furthermore, microglia-specific molecular mechanisms are largely unknown. This was largely because of the inability to manipulate microglia in a specific way without at least affecting peripheral immune cells of the same lineage and expressing a similar repertoire of genes (i.e., peripheral macrophages). New advances in Cre-lox technology have resulted in $C \times 3 c r 1^{\text {creER }}$ mice, which will allow for specific genetic manipulation in microglia after $1 \mathrm{wk}$ of tamoxifen treatment. In addition, recent work identifying genes to distinguish microglia from their peripheral cell counterparts offers exciting new advances for manipulating microglia in more specific ways (Chiu et al. 2013; Butovsky et al. 2014; Zhang et al. 2014). We are now entering a very exciting time. The identification of molecular mechanisms underlying interactions between microglia and other CNS cell types and translation of these mechanisms to functional consequences will offer enormous advancements. These advancements will range from understanding of basic principles of nervous system development and overall function to transla- 
D.P. Schafer and B. Stevens

tional neuroscience in which these basic mechanisms can be applied to neurological disease.

\section{ACKNOWLEDGMENTS}

All work performed by authors is supported by grants from the Smith Family Foundation (B.S.), the Dana Foundation (B.S.), the John Merck Scholars Program (B.S.), the National Institute of Neurological Disorders and Stroke (RO1-NS-07100801, B.S.; F32-NS-066698, D.P.S.), the Nancy Lurie Marks Foundation (D.P.S.), and the National Institute of Mental Health (K99-MH-102351, D.P.S.).

\section{REFERENCES}

Abrams JM, White K, Fessler LI, Steller H. 1993. Programmed cell death during Drosophila embryogenesis. Development 117: 29-43.

Alexander A, Barres B, Stevens B. 2012. The complement system: An unexpected role in synaptic pruning during development and disease. Annu Rev Neurosci 35: 369389.

Aliprantis AO, Diez-Roux G, Mulder LC, Zychlinsky A, Lang RA. 1996. Do macrophages kill through apoptosis? Immunol Today 17: 573-576.

Antony JM, Paquin A, Nutt SL, Kaplan DR, Miller FD. 2011. Endogenous microglia regulate development of embryonic cortical precursor cells. J Neurosci Res 89: 286-298.

Arnold SE. 1999. Neurodevelopmental abnormalities in schizophrenia: Insights from neuropathology. Dev Psychopathol 11: 439-456.

Bangs P, White K. 2000. Regulation and execution of apoptosis during Drosophila development. Dev Dyn 218: 68-79.

Barrientos RM, Higgins EA, Biedenkapp JC, Sprunger DB, Wright-Hardesty KJ, Watkins LR, Rudy JW, Maier SF. 2006. Peripheral infection and aging interact to impair hippocampal memory consolidation. Neurobiol Aging 27: 723-732.

Belmonte MK, Allen G, Beckel-Mitchener A, Boulanger LM, Carper RA, Webb SJ. 2004. Autism and abnormal development of brain connectivity. J Neurosci 24: 9228-9231.

Bence M, Levelt CN. 2005. Structural plasticity in the developing visual system. 147: 125-139.

Bessis A, Bechade C, Bernard D, Roumier A. 2007. Microglial control of neuronal death and synaptic properties. Glia 55: 233-238.

Bilbo SD, Schwarz JM. 2009. Early-life programming of later-life brain and behavior: A critical role for the immune system. Front Behav Neurosci 3: 14.

Bilbo SD, Schwarz JM. 2012. The immune system and developmental programming of brain and behavior. Front Neuroendocrinol 33: 267-286.
Bilbo SD, Levkoff LH, Mahoney JH, Watkins LR, Rudy JW, Maier SF. 2005. Neonatal infection induces memory impairments following an immune challenge in adulthood. Behav Neurosci 119: 293-301.

Bilbo SD, Rudy JW, Watkins LR, Maier SF. 2006. A behavioural characterization of neonatal infection-facilitated memory impairment in adult rats. Behav Brain Res 169: $39-47$.

Bilbo SD, Newsum NJ, Sprunger DB, Watkins LR, Rudy JW, Maier SF. 2007. Differential effects of neonatal handling on early life infection-induced alterations in cognition in adulthood. Brain Behav Immun 21: 332-342.

Blank T, Prinz M. 2013. Microglia as modulators of cognition and neuropsychiatric disorders. Glia 61: 62-70.

Brown GC, Neher JJ. 2014. Microglial phagocytosis of live neurons. Nat Rev Neurosci 15: 209-216.

Buller KM, Carty ML, Reinebrant HE, Wixey JA. 2009. Minocycline: A neuroprotective agent for hypoxic-ischemic brain injury in the neonate? J Neurosci Res 87: 599-608.

Butovsky O, Jedrychowski MP, Moore CS, Cialic R, Lanser AJ, Gabriely G, Koeglsperger T, Dake B, Wu PM, Doykan $\mathrm{CE}$, et al. 2014. Identification of a unique TGF- $\beta$-dependent molecular and functional signature in microglia. Nat Neurosci 17: 131-143.

Chamak B, Morandi V, Mallat M. 1994. Brain macrophages stimulate neurite growth and regeneration by secreting thrombospondin. J Neurosci Res 38: 221-233.

Chen C, Regehr WG. 2000. Developmental remodeling of the retinogeniculate synapse. Neuron 28: 955-966.

Chen SK, Tvrdik P, Peden E, Cho S, Wu S, Spangrude G, Capecchi MR. 2010. Hematopoietic origin of pathological grooming in Hoxb8 mutant mice. Cell 141: 775-785.

Chiu IM, Morimoto ET, Goodarzi H, Liao JT, O’Keeffe S, Phatnani HP, Muratet M, Carroll MC, Levy S, Tavazoie S, et al. 2013. A neurodegeneration-specific gene-expression signature of acutely isolated microglia from an amyotrophic lateral sclerosis mouse model. Cell Rep 4: 385-401.

Chung WS, Clarke LE, Wang GX, Stafford BK, Sher A, Chakraborty C, Joung J, Foo LC, Thompson A, Chen C, et al. 2013. Astrocytes mediate synapse elimination through MEGF10 and MERTK pathways. Nature 504: 394-400.

Coull JA, Beggs S, Boudreau D, Boivin D, Tsuda M, Inoue K, Gravel C, Salter MW, De Koninck Y. 2005. BDNF from microglia causes the shift in neuronal anion gradient underlying neuropathic pain. Nature 438: 1017-1021.

Cunningham CL, Martinez-Cerdeno V, Noctor SC. 2013. Microglia regulate the number of neural precursor cells in the developing cerebral cortex. J Neurosci 33: 42164233.

Dalmau I, Finsen B, Zimmer J, Gonzalez B, Castellano B. 1998. Development of microglia in the postnatal rat hippocampus. Hippocampus 8: 458-474.

Davalos D, Grutzendler J, Yang G, Kim JV, Zuo Y, Jung S, Littman DR, Dustin ML, Gan WB. 2005. ATP mediates rapid microglial response to local brain injury in vivo. Nat Neurosci 8: 752-758.

Derecki NC, Cronk JC, Kipnis J. 2012a. The role of microglia in brain maintenance: Implications for Rett syndrome. Trend Immunol 34: 144-150. 
Derecki NC, Cronk JC, Lu Z, Xu E, Abbott SB, Guyenet PG, Kipnis J. 2012b. Wild-type microglia arrest pathology in a mouse model of Rett syndrome. Nature 484: 105-109.

Elmore MR, Najafi AR, Koike MA, Dagher NN, Spangenberg EE, Rice RA, Kitazawa M, Matusow B, Nguyen H, West BL, et al. 2014. Colony-stimulating factor 1 receptor signaling is necessary for microglia viability, unmasking a microglia progenitor cell in the adult brain. Neuron 82: $380-397$.

Ferrer I, Bernet E, Soriano E, del Rio T, Fonseca M. 1990. Naturally occurring cell death in the cerebral cortex of the rat and removal of dead cells by transitory phagocytes. Neuroscience 39: 451-458.

Frade JM, Barde YA. 1998. Microglia-derived nerve growth factor causes cell death in the developing retina. Neuron 20: $35-41$.

Gasque P. 2004. Complement: A unique innate immune sensor for danger signals. Mol Immunol 41: 1089-1098.

Gebara E, Sultan S, Kocher-Braissant J, Toni N. 2013. Adult hippocampal neurogenesis inversely correlates with microglia in conditions of voluntary running and aging. Front Neurosci 7: 145.

Ginhoux F, Greter M, Leboeuf M, Nandi S, See P, Gokhan S, Mehler MF, Conway SJ, Ng LG, Stanley ER. 2010. Fate mapping analysis reveals that adult microglia derive from primitive macrophages. Science 330: 841.

Giovanoli S, Engler H, Engler A, Richetto J, Voget M, Willi R, Winter C, Riva MA, Mortensen PB, Schedlowski M, et al. 2013. Stress in puberty unmasks latent neuropathological consequences of prenatal immune activation in mice. Science 339: 1095-1099.

Goldmann T, Wieghofer P, Muller PF, Wolf Y, Varol D, Yona S, Brendecke SM, Kierdorf K, Staszewski O, Datta M, et al. 2013. A new type of microglia gene targeting shows TAK1 to be pivotal in CNS autoimmune inflammation. Nat Neurosci 16: 1618-1626.

Graeber MB. 2010. Changing face of microglia. Science 330: $783-788$.

Hagberg H, Mallard C. 2005. Effect of inflammation on central nervous system development and vulnerability. Curr Opin Neurol 18: 117-123.

Hamerman JA, Tchao NK, Lowell CA, Lanier LL. 2005. Enhanced Toll-like receptor responses in the absence of signaling adaptor DAP12. Nat Immunol 6: 579-586.

Harvey L, Boksa P. 2012. Prenatal and postnatal animal models of immune activation: Relevance to a range of neurodevelopmental disorders. Dev Neurobiol 72: 1335-1348.

Hooks BM, Chen C. 2006. Distinct roles for spontaneous and visual activity in remodeling of the retinogeniculate synapse. Neuron 52: 281-291.

Hooks BM, Chen C. 2007. Critical periods in the visual system: Changing views for a model of experience-dependent plasticity. Neuron 56: 312-326.

Hua JY, Smith SJ. 2004. Neural activity and the dynamics of central nervous system development. Nat Neurosci 7: $327-332$.

Huberman AD. 2007. Mechanisms of eye-specific visual circuit development. Curr Opin Neurobiol 17: 73-80.

Huberman AD, Feller MB, Chapman B. 2008. Mechanisms underlying development of visual maps and receptive fields. Annu Rev Neurosci 31: 479-509.
Kano M, Hashimoto K. 2009. Synapse elimination in the central nervous system. Curr Opin Neurobiol 19: 154-161.

Katz LC, Shatz CJ. 1996. Synaptic activity and the construction of cortical circuits. Science 274: 1133-1138.

Kettenmann H, Hanisch U, Noda M, Verkhratsky A. 2011. Physiology of microglia. Physiol Rev 91: 461-553.

Kettenmann H, Kirchhoff F, Verkhratsky A. 2013. Microglia: New roles for the synaptic stripper. Neuron 77: 10-18.

Kinet MJ, Shaham S. 2014. Noncanonical cell death in the nematode Caenorhabditis elegans. Methods Enzymol 545: $157-180$.

Kurant E. 2011. Keeping the CNS clear: Glial phagocytic functions in Drosophila. Glia 59: 1304-1311.

Lambris J, Tsokos G. 1986. The biology and pathophysiology of complement receptors. Anticancer Res 6: 515-523.

Lang RA, Bishop JM. 1993. Macrophages are required for cell death and tissue remodeling in the developing mouse eye. Cell 74: 453-462.

Lenz KM, Nugent BM, Haliyur R, McCarthy MM. 2013. Microglia are essential to masculinization of brain and behavior. J Neurosci 33: 2761-2772.

Lichtman J, Colman H. 2000. Synapse elimination and indelible memory. Neuron 25: 269.

Linnartz B, Kopatz J, Tenner AJ, Neumann H. 2012. Sialic acid on the neuronal glycocalyx prevents complement $\mathrm{Cl}$ binding and complement receptor-3-mediated removal by microglia. J Neurosci 32: 946-952.

Logan MA, Freeman MR. 2007. The scoop on the fly brain: Glial engulfment functions in Drosophila. Neuron Glia Biol 3: 63-74.

Lu Z, Elliott MR, Chen Y, Walsh JT, Klibanov AL, Ravichandran KS, Kipnis J. 2011. Phagocytic activity of neuronal progenitors regulates adult neurogenesis. Nat Cell Biol 13: $1076-1083$.

Maggi L, Trettel F, Scianni M, Bertollini C, Eusebi F, Fredholm BB, Limatola C. 2009. LTP impairment by fractalkine/CX3CL1 in mouse hippocampus is mediated through the activity of adenosine receptor type 3 (A3R). J Neuroimmunol 215: 36-42.

Majewska A, Sur M. 2003. Motility of dendritic spines in visual cortex in vivo: Changes during the critical period and effects of visual deprivation. Proc Natl Acad Sci 100: 16024-16029.

Marin-Teva JL, Dusart I, Colin C, Gervais A, van Rooijen N, Mallat M. 2004. Microglia promote the death of developing Purkinje cells. Neuron 41: 535-547.

Maslinska D, Laure-Kamionowska M, Kaliszek A. 1998. Morphological forms and localization of microglial cells in the developing human cerebellum. Folia Neuropathol 36: $145-151$.

Meier P, Finch A, Evan G. 2000. Apoptosis in development. Nature 407: 796-801.

Melom JE, Littleton JT. 2011. Synapse development in health and disease. Curr Opin Genet Dev 21: 256-261.

Meyer U, Feldon J, Fatemi SH. 2009. In vivo rodent models for the experimental investigation of prenatal immune activation effects in neurodevelopmental brain disorders. Neurosci Biobehav Rev 33: 1061-1079.

Milligan CE, Cunningham TJ, Levitt P. 1991. Differential immunochemical markers reveal the normal distribution 
D.P. Schafer and B. Stevens

of brain macrophages and microglia in the developing rat brain. J Comp Neurol 314: 125-135.

Mocsai A, Abram CL, Jakus Z, Hu Y, Lanier LL, Lowell CA. 2006. Integrin signaling in neutrophils and macrophages uses adaptors containing immunoreceptor tyrosinebased activation motifs. Nat Immunol 7: 1326-1333.

Monji A, Kato T, Kanba S. 2009. Cytokines and schizophrenia: Microglia hypothesis of schizophrenia. Psychiatry Clin Neurosci 63: 257-265.

Morgan SC, Taylor DL, Pocock JM. 2004. Microglia release activators of neuronal proliferation mediated by activation of mitogen-activated protein kinase, phosphatidylinositol-3-kinase/Akt and delta-Notch signalling cascades. J Neurochem 90: 89-101.

Morgan JT, Chana G, Pardo CA, Achim C, Semendeferi K, Buckwalter J, Courchesne E, Everall IP. 2010. Microglial activation and increased microglial density observed in the dorsolateral prefrontal cortex in autism. Biol Psychiatry 68: $368-376$.

Mower G, Christen W, Caplan C. 1983. Very brief visual experience eliminates plasticity in the cat visual cortex. Science 221: 178-180.

Nagata K, Nakajima K, Takemoto N, Saito H, Kohsaka S. 1993. Microglia-derived plasminogen enhances neurite outgrowth from explant cultures of rat brain. Int J Dev Neurosci 11: 227-237.

Napoli I, Neumann H. 2009. Microglial clearance function in health and disease. Neuroscience 158: 1030-1038.

Nimmerjahn A, Kirchhoff F, Helmchen F. 2005. Resting microglial cells are highly dynamic surveillants of brain parenchyma in vivo. Science 308: 1314-1318.

Oppenheim RW. 1991. Cell death during development of the nervous system. Annu Rev Neurosci 14: 453-501.

Paolicelli RC, Bolasco G, Pagani F, Maggi L, Scianni M, Panzanelli P, Giustetto M, Ferreira TA, Guiducci E, Dumas L, et al. 2011. Synaptic pruning by microglia is necessary for normal brain development. Science 333: 1456-1458.

Parkhurst CN, Yang G, Ninan I, Savas JN, Yates JR III, Lafaille JJ, Hempstead BL, Littman DR, Gan WB. 2013. Microglia promote learning-dependent synapse formation through brain-derived neurotrophic factor. Cell 155: 1596-1609.

Pascual O, Ben Achour S, Rostaing P, Triller A, Bessis A. 2011. Microglia activation triggers astrocyte-mediated modulation of excitatory neurotransmission. Proc Natl Acad Sci 109: E197-E205.

Patterson PH. 2009. Immune involvement in schizophrenia and autism: Etiology, pathology and animal models. Behav Brain Res 204: 313-321.

Peri F, Nusslein-Volhard C. 2008. Live imaging of neuronal degradation by microglia reveals a role for v0-ATPase al in phagosomal fusion in vivo. Cell 133: 916-927.

Perry VH, Hume DA, Gordon S. 1985. Immunohistochemical localization of macrophages and microglia in the adult and developing mouse brain. Neuroscience 15: 313-326.

Perry VH, Cunningham C, Holmes C. 2007. Systemic infections and inflammation affect chronic neurodegeneration. Nat Rev Immunol 7: 161-167.

Philpot B, Sekhar A, Shouval H, Bear M. 2001. Visual experience and deprivation bidirectionally modify the com- position and function of NMDA receptors in visual cortex. Neuron 29: 157-169.

Pollard JW. 2009. Trophic macrophages in development and disease. Nat Rev Immunol 9: 259-270.

Purves D, Lichtman JW. 1980. Elimination of synapses in the developing nervous system. Science 210: 153-157.

Ransohoff RM, Cardona AE. 2010. The myeloid cells of the central nervous system parenchyma. Nature 468: $253-$ 262.

Ransohoff RM, Perry VH. 2009. Microglial physiology: Unique stimuli, specialized responses. Anпu Rev Immunol 27: 119-145.

Ransohoff RM, Stevens B. 2011. Neuroscience. How many cell types does it take to wire a brain? Science 333: 1391 1392.

Ribak CE, Shapiro LA, Perez ZD, Spigelman I. 2009. Microglia-associated granule cell death in the normal adult dentate gyrus. Brain Struct Funct 214: 25-35.

Rogers JT, Morganti JM, Bachstetter AD, Hudson CE, Peters MM, Grimmig BA, Weeber EJ, Bickford PC, Gemma C. 2011. CX3CR1 deficiency leads to impairment of hippocampal cognitive function and synaptic plasticity. $J$ Neurosci 31: 16241-16250.

Rogulja-Ortmann A, Luer K, Seibert J, Rickert C, Technau GM. 2007. Programmed cell death in the embryonic central nervous system of Drosophila melanogaster. Development 134: 105-116.

Roumier A, Bechade C, Poncer JC, Smalla KH, Tomasello E, Vivier E, Gundelfinger ED, Triller A, Bessis A. 2004. Impaired synaptic function in the microglial KARAP/ DAP12-deficient mouse. J Neurosci 24: 11421-11428.

Roumier A, Pascual O, Bechade C, Wakselman S, Poncer JC, Real E, Triller A, Bessis A. 2008. Prenatal activation of microglia induces delayed impairment of glutamatergic synaptic function. PloS ONE 3: e2595.

Salter MW, Beggs S. 2014. Sublime microglia: Expanding roles for the guardians of the CNS. Cell 158: 15-24.

Sanes JR, Lichtman JW. 1999. Development of the vertebrate neuromuscular junction. Annu Rev Neurosci 22: 389442.

Schafer DP, Stevens B. 2010. Synapse elimination during development and disease: Immune molecules take centre stage. Biochem Soc Trans 38: 476-481.

Schafer DP, Stevens B. 2013. Phagocytic glial cells: Sculpting synaptic circuits in the developing nervous system. Curr Opin Neurobiol 23: 1034-1040.

Schafer DP, Lehrman EK, Kautzman AG, Koyama R, Mardinly AR, Yamasaki R, Ransohoff RM, Greenberg ME, Barres BA, Stevens B. 2012. Microglia sculpt postnatal neural circuits in an activity and complement-dependent manner. Neuron 74: 691-705.

Schafer DP, Lehrman EK, Stevens B. 2013. The "quad-partite" synapse: Microglia-synapse interactions in the developing and mature CNS. Glia 61: 24-36.

Schafer DP, Lehrman EK, Heller CT, Stevens B. 2014. An engulfment assay: A protocol to assess interactions between CNS phagocytes and neurons. J Vis Exp doi: $10.3791 / 51482$.

Schwarz JM, Bilbo SD. 2012. Sex, glia, and development: Interactions in health and disease. Horm Behav 62: 243-253. 
Schwarz JM, Sholar PW, Bilbo SD. 2012. Sex differences in microglial colonization of the developing rat brain. $J$ Neurochem 120: 948-963.

Sedel F, Bechade C, Vyas S, Triller A. 2004. Macrophagederived tumor necrosis factor $\alpha$, an early developmental signal for motoneuron death. J Neurosci 24: 2236-2246.

Sierra A, Encinas JM, Deudero JJ, Chancey JH, Enikolopov G, Overstreet-Wadiche LS, Tsirka SE, Maletic-Savatic M. 2010. Microglia shape adult hippocampal neurogenesis through apoptosis-coupled phagocytosis. Cell Stem Cell 7: 483-495.

Sierra A, Abiega O, Shahraz A, Neumann H. 2013. Janusfaced microglia: Beneficial and detrimental consequences of microglial phagocytosis. Front Cell Neurosci 7: 6.

Smilack JD. 1999. The tetracyclines. Mayo Clin Proc 74: 727-729.

Song J, Christian KM, Ming GL, Song H. 2012. Modification of hippocampal circuitry by adult neurogenesis. Dev Neurobiol 72: 1032-1043.

Stevens B, Allen NJ, Vazquez LE, Howell GR, Christopherson KS, Nouri N, Micheva KD, Mehalow AK, Huberman AD, Stafford B, et al. 2007. The classical complement cascade mediates CNS synapse elimination. Cell 131: 1164-1178.

Sulston JE, Horvitz HR. 1977. Post-embryonic cell lineages of the nematode, Caenorhabditis elegans. Dev Biol 56: $110-156$.

Sultan S, Gebara E, Toni N. 2013. Doxycycline increases neurogenesis and reduces microglia in the adult hippocampus. Front Neurosci 7: 131

Tomasello E, Olcese L, Vely F, Geourgeon C, Blery M, Moqrich A, Gautheret D, Djabali M, Matteii M, Vivier E. 1998 Gene structure, expression pattern, and biological activity of mouse killer cell activating receptor-associated protein (KARAP)/DAP-12. J Biol Chem 273: 34115-34119.

Tomasello E, Desmoulins P, Chemin K, Guia S, Cremer H, Ortaldo J, Love P, Kaiserlian D, Vivier E. 2000. Combined natural killer cell and dendritic cell functional deficiency in KARAP/DAP12 loss-of-function mutant mice. Immunity 13: 355-364.

Tremblay ME. 2011. The role of microglia at synapses in the healthy CNS: Novel insights from recent imaging studies. Neuron Glia Biol 7: 67-76.

Tremblay ME, Lowery RL, Majewska AK. 2010. Microglial interactions with synapses are modulated by visual experience. PLoS Biol 8: e1000527.

Tremblay ME, Stevens B, Sierra A, Wake H, Bessis A, Nimmerjahn A. 2011. The role of microglia in the healthy brain. J Neurosci 31: 16064-16069.

Tropea D, Majewska AK, Garcia R, Sur M. 2010. Structural dynamics of synapses in vivo correlate with functional changes during experience-dependent plasticity in visual cortex. J Neurosci 30: 11086-11095.

Tsuda M, Shigemoto-Mogami Y, Koizumi S, Mizokoshi A, Kohsaka S, Salter M, Inoue K. 2003. P2X4 receptors induced in spinal microglia gate tactile allodynia after nerve injury. Nature 424: 778-783.

Turnbull IR, McDunn JE, Takai T, Townsend RR, Cobb JP, Colonna M. 2005. DAP12 (KARAP) amplifies inflammation and increases mortality from endotoxemia and septic peritonitis. J Exp Med 202: 363-369.
Ueno M, Fujita Y, Tanaka T, Nakamura Y, Kikuta J, Ishii M, Yamashita T. 2013. Layer V cortical neurons require microglial support for survival during postnatal development. Nat Neurosci 16: 543-551.

van Lookeren Campagne M, Wiesmann C, Brown EJ. 2007. Macrophage complement receptors and pathogen clearance. Cell Microbiol 9: 2095-2102.

Vargas DL, Nascimbene C, Krishnan C, Zimmerman AW, Pardo CA. 2005. Neuroglial activation and neuroinflammation in the brain of patients with autism. Ann Neurol 57: $67-81$.

Vaux DL, Korsmeyer SJ. 1999. Cell death in development. Cell 96: $245-254$.

Viegi A, Cotrufo T, Berardi N, Mascia L, Maffei L. 2002. Effects of dark rearing on phosphorylation of neurotrophin Trk receptors. Eur J Neurosci 16: 1925-1930.

Waites CL, Garner CC. 2011. Presynaptic function in health and disease. Trends Neurosci 34: 326-337.

Wake H, Moorhouse AJ, Miyamoto A, Nabekura J. 2013. Microglia: Actively surveying and shaping neuronal circuit structure and function. Trends Neurosci 36: 209-217.

Wakselman S, Bechade C, Roumier A, Bernard D, Triller A Bessis A. 2008. Developmental neuronal death in hippocampus requires the microglial $\mathrm{CD} 11 \mathrm{~b}$ integrin and DAP12 immunoreceptor. J Neurosci 28: 8138-8143.

Wierzba-Bobrowicz T, Kosno-Kruszewska E, Gwiazda E, Lechowicz W. 1998. The comparison of microglia maturation in different structures of the human nervous system. Folia Neuropathol 36: 152-160.

Williamson LL, Sholar PW, Mistry RS, Smith SH, Bilbo SD. 2011. Microglia and memory: Modulation by early-life infection. J Neurosci 31: 15511-15521.

Woo TU, Crowell AL. 2005. Targeting synapses and myelin in the prevention of schizophrenia. Schizophr Res 73: 193-207.

Wyss-Coray T, Mucke L. 2002. Inflammation in neurodegenerative disease-A double-edged sword. Neuron 35: 419-432.

Yeo W, Gautier J. 2004. Early neural cell death: Dying to become neurons. Dev Biol 274: 233-244.

Yona S, Kim KW, Wolf Y, Mildner A, Varol D, Breker M, Strauss-Ayali D, Viukov S, Guilliams M, Misharin A, et al. 2013. Fate mapping reveals origins and dynamics of monocytes and tissue macrophages under homeostasis. Immunity 38: 79-91.

Zhan Y, Paolicelli RC, Sforazzini F, Weinhard L, Bolasco G, Pagani F, Vyssotski AL, Bifone A, Gozzi A, Ragozzino D, et al. 2014. Deficient neuron-microglia signaling results in impaired functional brain connectivity and social behavior. Nat Neurosci 17: 400-406.

Zhang Y, Chen K, Sloan SA, Bennett ML, Scholze AR, O'Keeffe S, Phatnani HP, Guarnieri P, Caneda C, Ruderisch N, et al. 2014. An RNA-sequencing transcriptome and splicing database of glia, neurons, and vascular cells of the cerebral cortex. J Neurosci 34: 11929-11947.

Zhou Z, Hartwieg E, Horvitz HR. 2001. CED-1 is a transmembrane receptor that mediates cell corpse engulfment in C. elegans. Cell 104: 43-56. 


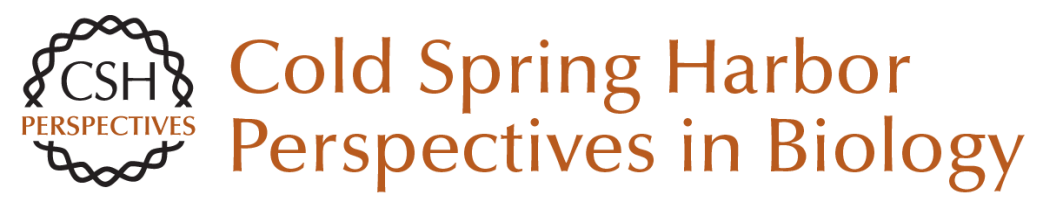

\section{Microglia Function in Central Nervous System Development and Plasticity}

Dorothy P. Schafer and Beth Stevens

Cold Spring Harb Perspect Biol 2015; doi: 10.1101/cshperspect.a020545 originally published online July 17,2015

\section{Subject Collection Glia}

The Nodes of Ranvier: Molecular Assembly and Maintenance Matthew N. Rasband and Elior Peles

Microglia in Health and Disease Richard M. Ransohoff and Joseph El Khoury

The Astrocyte: Powerhouse and Recycling Center Bruno Weber and L. Felipe Barros

Microglia Function in Central Nervous System Development and Plasticity Dorothy P. Schafer and Beth Stevens

Transcriptional and Epigenetic Regulation of Oligodendrocyte Development and Myelination in the Central Nervous System Ben Emery and Q. Richard Lu

Origin of Microglia: Current Concepts and Past Controversies

Florent Ginhoux and Marco Prinz

Glia Disease and Repair--Remyelination Robin J.M. Franklin and Steven A. Goldman

Astrocytes in Neurodegenerative Disease Hemali Phatnani and Tom Maniatis
Oligodendrocyte Development and Plasticity Dwight E. Bergles and William D. Richardson

Oligodendrocytes: Myelination and Axonal

Support Mikael Simons and Klaus-Armin Nave

Drosophila Central Nervous System Glia Marc R. Freeman

Perisynaptic Schwann Cells at the Neuromuscular Synapse: Adaptable, Multitasking Glial Cells Chien-Ping Ko and Richard Robitaille

Astrocytes Control Synapse Formation, Function, and Elimination Won-Suk Chung, Nicola J. Allen and Cagla Eroglu

Schwann Cell Myelination James L. Salzer

Schwann Cells: Development and Role in Nerve Repair Kristján R. Jessen, Rhona Mirsky and Alison C. Lloyd

Perineurial Glia Sarah Kucenas

For additional articles in this collection, see http://cshperspectives.cshlp.org/cgi/collection/

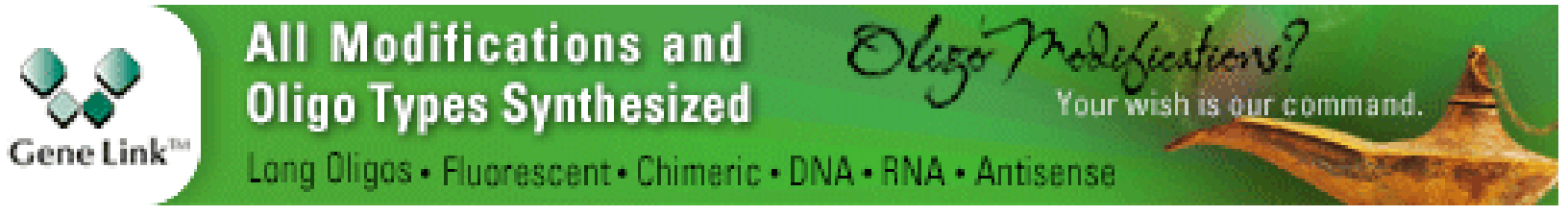

